\title{
ANALISA PERBANDINGAN PENAMBAHAN VARIASI CONSOL TERHADAP KUAT TEKAN BETON
}

\author{
Gusneli Yanti \\ Program Studi Teknik Sipil Universitas Lancang Kuning \\ Jalan Yos Sudarso Km. 8 Rumbai Pekanbaru \\ E-mail : gusneli@unilak.ac.id \\ Zainuri \\ Program Studi Teknik Sipil Universitas Lancang Kuning \\ Jalan Yos Sudarso Km. 8 Rumbai Pekanbaru \\ E-mail : zainuri@unilak.ac.id \\ Shanti Wahyuni Megasari \\ Program Studi Teknik Sipil Universitas Lancang Kuning \\ Jalan Yos Sudarso Km. 8 Rumbai Pekanbaru \\ E-mail : shanti@unilak.ac.id
}

\begin{abstract}
Abstrak
Perkembangan konstruksi bangunan memberikan tuntutan pada teknologi bahan material bangunan yang lebih efektif, cepat, ekonomis dan ramah lingkungan. Kondisi tersebut akhirnya menuntut material beton untuk terus dimodifikasi sehingga dapat memenuhi permintaan yang ada. Salah satu upaya dalam meningkatkan kualitas dan kuantitas beton yang dihasilkan adalah dengan memberikan bahan tambah (admixture) pada campuran beton. Consol merupakan bahan tambah (admixture) yang dapat mengurangi air, ada beberapa jenis Consol diantaranya Consol N10 MB yang ramah lingkungan, Consol SG berupa cairan plasticizer beton dengan efek memperlambat proses pengeringan. Untuk pemakaian bahan tambah perlu diperhatikan volume takaran yang sesuai dengan rencana. Perancangan beton menggunakan metode Department of Environment (DOE) dengan cetakan sampel berbentuk silinder ukuran diameter 150 $\mathrm{mm}$ dan tinggi $300 \mathrm{~mm}$. Persentase penambahan bahan tambah Consol N10 MB, Consol SG $0 \%, 0,1 \%, 0,3 \%, 0,5 \%, 0,8 \%, 1 \%$, dan $1,2 \%$ serta waktu pengujian tekan beton dilaksanakan pada umur 28 hari. Hasil Pengujian menunjukkan dengan penambahan Consol N10MB diperoleh peningkatan kuat tekan beton rata-rata hingga $0,3 \%$, dengan nilai kuat tekan beton rata-rata tertinggi sebesar 26,725 $\mathrm{MPa}$. Namun kemudian mengalami penurunan kekuatan tekan beton seiring dengan penambahan persentase Consol N10MB, dengan persamaan yang diperoleh yaitu $\mathrm{y}=-17,85 \mathrm{x}^{2}+$ $14,63 x+23,16$ dengan nilai $R^{2}=0,983$, dan dengan penambahan Consol SG diperoleh peningkatan kuat tekan beton rata-rata seiring dengan penambahan persentase Consol SG hingga penambahan $1,0 \%$, dengan nilai kuat tekan beton rata-rata tertinggi sebesar 46,144 MPa. Namun kemudian mengalami penurunan kekuatan tekan beton pada penambahan $1,2 \%$ Consol SG, dengan persamaan yang diperoleh yaitu $\mathrm{y}=-35,13 \mathrm{x}^{2}+$ $54,03 \mathrm{x}+24,43$ dengan nilai $\mathrm{R}^{2}=0,927$
\end{abstract}

Kata Kunci : Admixture, Beton, Consol, Kuat Tekan 


\begin{abstract}
The development of building construction provides demands on building materials technology more effective, fast, economical and environmentally friendly. The condition ultimately requires concrete material to continue to be modified so as to meet the existing demand. One of the efforts in improving the quality and quantity of concrete produced is to provide additional ingredients (admixture) to the concrete mix. Consol is an additive (admixture) that can reduce water, there are several Consol types Console $N 10 \mathrm{MB}$ is environmentally friendly, Consol SG in the form of liquid plasticizer concrete with the effect of slowing the drying process. For the use of added materials to note the volume of doses in accordance with the plan. Concrete design using Department of Environment (DOE) method with cylindrical sample mold size $150 \mathrm{~mm}$ diameter and height $300 \mathrm{~mm}$. Percentage of additives added Consol N10 MB, Consol $S G 0 \%, 0,1 \%, 0,3 \%, 0,5 \%, 0,8 \%, 1 \%$, and $1,2 \%$ and concrete press testing time was done at age 28 day. Testing results showed that with the addition of Consol N1OMB obtained an increase in compressive strength of concrete averaged up to $0.3 \%$, with the highest concrete compressive strength value of 26,725 MPa. But then decreased the compressive strength of concrete along with the addition of Consol N1OMB percentage, with the obtained equation that is $y=-17,85 x 2+14,63 x+23,16$ with value $R^{2}=0,983$, and with addition of Consol SG obtained increase of compressive strength of concrete flat in line with the addition of Consol SG percentage to 1,0\% increase, with the highest average concrete compressive value of 46,144 MPa. But then decreased the compressive strength of concrete on the addition of 1,2\% Consol SG, with the obtained equation is $y=-35,13 x 2+54,03 x+24,43$ with value $R^{2}=0,927$
\end{abstract}

Keywords : Admixture, Concrete, Compressive Strength, Consol

\section{A. PENDAHULUAN}

Salah satu upaya dalam meningkatkan kualitas dan kuantitas beton adalah dengan memberikan bahan tambah (admixture) pada campuran beton. Bahan tambah memiliki sifatsifat yang tidak diperoleh dari material beton konvensional, fungsi yang dibutuhkan pada campuran beton antara lain untuk meningkatkan nilai kekuatan tekan beton, mempercepat proses pengerasan, memperlambat proses pengeringan, mengurangi penggunaan jumlah air dan sebagainya, sehingga dapat mempermudah dan mempercepat proses pelaksanaan pembangunan serta memperkuat struktur bangunan.

Bahan tambah yang beredar di pasaran memiliki merek, jenis dan keunggulan yang berbeda-beda. Namun karena memiliki keunggulan tersendiri, maka harga dari bahan tambah relatif mahal.

PT. Kimia Konstruksi Indonesia memproduksi chemical construction berkualitas tinggi buatan anak bangsa. PT. Kimia Konstruksi Indonesia menciptakan Consol, serangkaian produk kimia konstruksi yang berkualitas tinggi, berdaya tahan lama, mudah dalam pengaplikasian dan harga yang lebih ekonomis. Consol memiliki berbagai jenis produk dengan keunggulan yang berbeda antara lain Consol N10 MB merupakan bahan tambah (admixture) untuk beton dengan kekuatan tinggi, Consol SG merupakan bahan tambah (admixture) untuk mengurangi jumlah air dan memperlambat proses pengeringan dan Consol P200-R1 merupakan bahan 
tambah (admixture) untuk mengurangi jumlah air dalam jumlah besar dan superplaticizer (PT. Concrete Technology Indonesia, 2017).

Pada Technical Data Sheet PT. Concrete Technology Indonesia (2017), dosis atau takaran penggunaan produk consol ada yang hanya dalam bentuk kisaran persentase sesuai dengan kondisi agregat maupun perencanaan. Kondisi tersebut tentu saja mempersulit masyarakat baik penyedia jasa dan pengguna jasa konstruksi khususnya di Kota Pekanbaru karena belum diketahui dengan jelas dosis atau takaran yang sesuai dengan kondisi material baik semen maupun agregat yang tersedia di Kota Pekanbaru.

Sehingga untuk mendapatkan hasil maksimal yang dapat diaplikasikan secara luas oleh masyarakat baik penyedia jasa dan pengguna jasa konstruksi di Kota Pekanbaru, akan dibutuhkan penelitian untuk dapat mengukur kemampuan beton yang dihasilkan dengan memberikan persentase variasi bahan tambah terhadap pengujian karakteristik kuat tekan beton.

\section{B. TINJAUAN PUSTAKA}

\section{Bahan Tambah (Admixture)}

Berdasarkan Nugraha P. dan Antoni, (2007), admixture atau bahan tambah adalah material selain air, agregat dan semen hidrolik yang dicampur dalam beton atau mortar yang ditambahkan sebelum atau selama pengadukan berlangsung.

Menurut Aprilianti, S. dan Nadia (2012) , untuk menghasilkan beton dengan fas rendah namun tetap mudah dikerjakan maka dibutuhkan bahan tambah, salah satunya menggunakan admixture superplasticizer. Dengan kemampuan mengurangi penggunaan air yang tinggi, campuran beton dengan bahan tambah mampu menghasilkan kuat tekan beton yang lebih tinggi.

Menurut Muliadi, Yanti, G. dan Megasari, S.W., (2015), tentang analisa perbandingan variasi waktu pengadukan terhadap kuat tekan beton dengan bahan tambah Sika Viscocrete-3115D. Hasil pengujian nilai kuat tekan beton pada beton tanpa bahan tambah mengalami penurunan dengan bertambahnya waktu pengadukan, sedangkan pada beton dengan tambahan mengalami kenaikan nilai kuat tekan beton. Dari hasil penelitian perbandingan variasi waktu pengadukan terhadap kuat tekan beton dengan bahan tambah Sika Viscocrete, diperoleh nilai kuat tekan beton tertinggi sebesar 29,22 $\mathrm{MPa}$ dengan tambahan Sika Viscocrete sebesar 0,2 \% dan tambahan waktu pengadukan 90 menit.

Megasari, S.W. dan Winayati (2017), menganalisis pengaruh variasi persentase bahan tambah Sikament-NN terhadap karakteristik kuat tekan beton. Hasil pengujian menunjukkan bahwa kecenderungan (trend) grafik kuat tekan rata-rata mengalami peningkatan dengan penambahan persentase Sikament-NN sebesar $1,3 \%$ dan 1,8\%. Persamaan yang dihasilkan dari kuat tekan rata-rata adalah $\mathrm{y}=-0,551 \mathrm{x}^{2}+6,791 \mathrm{x}+23,81$. Nilai kuat tekan rata-rata tertinggi diperoleh pada penambahan 1,8\% Sikament-NN yaitu sebesar 38,65 MPa. Pengujian statistik dengan menggunakan analisis varians (Analysis of Variance - ANOVA) menyatakan bahwa terdapat interaksi atau perlakuan yang sangat nyata antara kuat tekan beton dengan penambahan SikamentNN. Sehingga dapat disimpulkan bahwa penambahan Sikament-NN berpengaruh terhadap peningkatan karakteristik kuat tekan beton.

\section{Consol SG}

Menurut Technical Data Sheet PT. 
Concrete Technology Indonesia (2017), Consol SG merupakan bahan tambah (admixture) cairan plasticizer beton dan dapat mengurangi air dalam jumlah yang besar dengan efek memperlambat proses pengeringan. Penggunaan Consol SG sesuai dengan ASTM C494-92 untuk bahan tambah jenis D.

Consol SG digunakan untuk memperoleh beton kualitas tinggi, dapat diterapkan pada :
a. Temperatur tinggi
b. Fair faced concrete
c. Pumped concrete
d. Beton ready mix
e. Pengecoran pada areal yang besar dalam satu waktu pelaksanaan
f. Harus memiliki kekuatan mekanik yang tinggi

Consol SG memberikan keuntungan sebagai berikut :
a. Meningkatkan setting time pada cuaca panas, mempercepat pengerasan setelah setting.
b. Meningkatkan workability tanpa menambah jumlah air
c. Mengurangi jumlah air tanpa kehilangan workability

d. Meningkatkan kekuatan

e. Mengurangi rangkak dan susut

f. Dapat mengontrol ketahanan terhadap kehilangan nilai slump

g. Hasil permukaan yang lebih baik

h. Bebas chloride sehingga tidak merusak tulangan

Karakteristik dari Consol SG dapat dilihat pada tabel 1 .

Tabel 1. Karakteristik Consol SG

\begin{tabular}{ll}
\hline \multicolumn{1}{c}{ Data Teknis } \\
\hline Jenis & Polyhydroxy Carbon Salts \\
\hline Warna & Kuning Terang \\
\hline Kemasan & Drum 200 liter \\
\hline Berat Jenis & $1,17 \pm 0,01 \mathrm{~kg} / \mathrm{L}$ \\
\hline Umur dan Penyimpanan & Minimal 1 tahun apabila disimpan dalam kemasan asli yang \\
& belum dibuka pada tempat yang kering, sejuk dan teduh \\
\hline Kemasan & Drum 240 liter \\
\hline Dosis atau Takaran & Dosis pemakaian Consol SG adalah 0,15\% $0,40 \%$ terhadap \\
& berat semen. \\
& Dosis ini dapat ditingkatkan sampai dengan 0,40\% untuk \\
& mengatasi kesulitan dalam hal kualitas semen maupun \\
& agregat, temperatur yang tinggi dan sulitnya kondisi \\
& pengecoran. \\
& Disarankan untuk melalukan percobaan untuk menetapkan \\
& tingkat dosis atau takaran yang tepat sesuai dengan \\
& kebutuhan. \\
Consol SG sesuai dengan seluruh jenis semen portland. \\
Consol SG harus dicampur terlebih dahulu dengan air \\
sebelum ditungkan ke dalam agregat. \\
Bila terjadi kelebihan dosis, Consol SG tidak memiliki \\
gelembung udara sehingga peningkatan proses pengeringan \\
tetap terjadi. Selama proses tersebut, beton harus dijaga \\
kelembabannya sehingga tidak terjadi pengeringan yang lebih \\
awal.
\end{tabular}

(Sumber : Technical Data Sheet PT. Concrete Technology Indonesia, 2017)

Consol N10 MB memberikan keuntungan sebagai berikut :

1. Workability yang sangat tinggi, dengan waktu pelaksanaan yang singkat sehingga dapat menghemat waktu dan tenaga. 
2. Pengurangan jumlah air yang besar, impermeability dan kekuatan yang tinggi sehingga dapat meningkatkan durabilitas.

3. Daya lekat (kohesi) yang sangat tinggi, tidak menimbulkan segregasi walaupun dengan workability yang tinggi, sehingga dapat meningkatkan kualitas beton yang dihasilkan.

4. Kekuatan awal yang tinggi
5. Modulus elastisitas yang tinggi, sehingga kapasitaebanan menjadi sangat tinggi

6. Rangkak dan susut yang rendah, sehingga lebih baik dalam stabilitas dimensi yang dihasilkan.

Karakteristik dari Consol N10 MB dapat dilihat pada Tabel 2 .

Tabel 2. Karakteristik Consol N10 MB

\begin{tabular}{ll}
\hline & \multicolumn{1}{c}{ Data Teknis } \\
\hline Bahan Kimia Dasar & Naphatalene Sulphonated \\
\hline Bentuk & Cairan \\
\hline Warna & Coklat Tua \\
\hline Kemasan & Drum 200 liter \\
\hline Berat Jenis & $1,18 \pm 0,01 \mathrm{~kg} / \mathrm{L}\left(\right.$ at $\left.25^{\circ}\right)-1,20 \mathrm{~kg} / \mathrm{ltr}$ \\
\hline Umur dan Penyimpanan & Minimal 1 tahun apabila disimpan dalam kemasan asli yang \\
& belum dibuka, harus disimpan pada suhu di atas 0 pada drum \\
& aslinya. Apabila telah membeku, maka cairkan dan dapat \\
& dipergunakan kembali \\
\hline Kemasan & Drum 200 liter \\
\hline Dosis atau Takaran & Dosis tergantung kepada perencanaan campuran, kondisi \\
& sekitar, derajat reduksi air dan workability yang diperlukan. \\
& Dosis tipikal yang digunakan adalah 0,6 - $1,5 \%$ terhadap \\
& berat semen. \\
& Disarankan untuk melalukan percobaan untuk menetapkan \\
& tingkat dosis atau takaran yang tepat sesui dengan kebutuhan. \\
\hline Tidak direkomendasikan untuk menambahan Consol N10 \\
MB dalam kondisi campuran kering. \\
Pencampuran beton membutuhkan sekitar $75-80 \%$ dari total \\
air campuran untuk menghasilkan campuran yang kaku, \\
lembab dan homogen. \\
Tambahkan Consol N10 MB pada beton dengan dosis yang \\
telah ditentukan. Campur paling sedikit selama 3 menit. \\
Selama pencampuran, tambahkan sisa air hingga diperoleh \\
workability yang diharapkan. \\
Penggunaan fly-ash atau silica fume dapat bermanfaat dalam \\
produksi beton yang lebih kohesif. Fly-ash atau silica fume \\
dapat ditambahkan dengan semen.
\end{tabular}

(Sumber: Technical Data Sheet PT. Concrete Technology Indonesia, 2017)

C. DATA DAN ANALISA DATA

\section{Material Penelitian}

Material yang digunakan adalah :

1. Semen, semen yang digunakan adalah semen Tipe I (Portland Composite Cement - PCC), produksi PT. Semen Padang kemasan $50 \mathrm{~kg}$

2. Agregat kasar, agregat kasar atau batu pecah yang digunakan yaitu agregat kasar yang berasal dari daerah Batu Bersurat

3. Agregat halus, agregat halus (pasir) 
yang digunakan adalah pasir yang berasal dari daerah Batu Bersurat.

4. Air, air yang digunakan berasal dari air bersih pada Laboratorium Batching Plant PT. Mekar Abadi Mandiri Jalan Lintas Pekanbaru Duri Km.62

5. Bahan Tambah, bahan tambah yang digunakan adalah Consol N10 MB dan Consol SG produksi PT. Concrete Technology Indonesia.

\section{Rancangan Benda Uji}

Penelitian ini dilakukan dengan cara memberikan variasi persentase penambahan Consol N10 MB dan Consol SG terhadap kuat tekan beton.

Perancangan beton menggunakan metode Departement of Environment
(DOE), dengan cetakan selinder dengan ukuran $150 \mathrm{~mm}$ x $300 \mathrm{~mm}$. Kuat tekan rencana yang digunakan sesuai dengan kuat tekan yang biasa digunakan yaitu $\mathrm{f}_{\mathrm{c}}{ }^{\prime}=18,86 \mathrm{MPa}$.

Awal penelitian dimulai dengan melakukan pengujian pendahuluan pada material, pembuatan benda uji, pengecekan nilai slump, tahapan perawatan (perendaman) selama 28 (dua puluh delapan) hari dan dilaksanakan pengujian tekan pada umur 28 (dua puluh depalan) hari. Hasil dari pengujian tekan tersebut dilanjutkan dengan analisis data.

Adapun rincian benda uji dapat dilihat pada tabel 3 .

Tabel 3. Rancangan Benda Uji

\begin{tabular}{|l|c|c|c|c|c|c|c|c|}
\hline \multirow{2}{*}{ Bahan Tambah } & \multicolumn{7}{|c|}{ \% Penambahan } & \multirow{2}{*}{ Jumlah } \\
\cline { 1 - 11 } & 0 & 0,1 & 0,3 & 0,5 & 0,8 & 1 & 1,2 & \\
\cline { 1 - 10 } 1. Consol N10 MB & \multirow{2}{*}{6} & 6 & 6 & 6 & 6 & 6 & 6 & 39 \\
\cline { 1 - 9 } 2. Consol SG & 6 & 6 & 6 & 6 & 6 & 39 \\
\hline
\end{tabular}

\section{Analisis Kuat Tekan Beton}

Perhitungan nilai kuat tekan dapat digunakan rumus :

$$
\mathrm{f}_{\mathrm{c}}^{\prime} \quad=\quad \frac{\mathrm{P}_{\max }}{\mathrm{A}_{\mathrm{C}}}
$$

\section{Dengan :}

$\mathrm{f}_{\mathrm{c}}^{\prime} \quad=$ Kuat tekan beton $(\mathrm{MPa})$

$\mathrm{P}_{\max }=$ Beban maksimum $(\mathrm{N})$

$\mathrm{A}_{\mathrm{c}} \quad=$ Luas permukaan $\left(\mathrm{mm}^{2}\right)$

Dari hasil nilai kuat tekan tersebut, maka dapat dilakukan analisis karakteristik kuat tekan beton dengan variasi persentase penambahan Consol N10 MB dan Consol SG.

\section{HASIL DAN PEMBAHASAN}

1. Hasil Pengujian Kuat Tekan
Hasil pengujian terhadap benda uji menunjukkan bahwa terjadi terhadap nilai kuat tekan beton dengan penambahan variasi persentase Consol N10 MB dan Consol SG masing-masing sebesar $0 \%, 0,1 \%, 0,3 \%, 0,5 \%, 0,8 \%$, $1 \%$, dan $1,2 \%$ terhadap berat semen.

Hasil pengujian tekan beton pada benda uji dapat dilihat pada Tabel 4

\section{Pembahasan}

Pada penelitian ini digunakan agregat kasar dan agregat halus yang berasal dari Batu Bersurat. Berdasarkan hasil pengujian pendahuluan material diperoleh bahwa agregat kasar dan agregat halus sesuai dengan persyaratan sebagai bahan campuran beton.

Hubungan Persentase Penambahan Consol N10MB dan Consol SG seperti terlihat pad Gambar 1 
Pada benda uji dengan penambahan Consol N10MB diperoleh peningkatan kuat tekan beton rata-rata hingga $0,3 \%$, dengan nilai kuat tekan beton rata-rata tertinggi sebesar 26,725 MPa. Namun kemudian mengalami penurunan kekuatan tekan beton seiring dengan penambahan \% Consol N10MB, dengan persamaan yang diperoleh yaitu $\mathrm{y}=-17,85 \mathrm{x}^{2}+14,63 \mathrm{x}+23,16$ dengan nilai $\mathrm{R}^{2}=0,983$.

Tabel 4. Hasil Pengujian Kuat Tekan Beton

\begin{tabular}{|c|c|c|c|c|}
\hline Bahan Tambah & $\%$ & Sampel & Kuat Tekan & $\begin{array}{c}\text { Kuat Tekan Rata-rata } \\
\text { (MPa) }\end{array}$ \\
\hline \multirow[t]{21}{*}{ Consol N10MB } & \multirow[t]{3}{*}{0,0} & $\mathrm{I}$ & 23,65 & \multirow[t]{3}{*}{22,591} \\
\hline & & II & 22,21 & \\
\hline & & III & 21,92 & \\
\hline & \multirow[t]{3}{*}{0,1} & $\mathrm{I}$ & 20,76 & \multirow[t]{3}{*}{24,706} \\
\hline & & II & 25,38 & \\
\hline & & III & 27,97 & \\
\hline & \multirow[t]{3}{*}{0,3} & $\mathrm{I}$ & 28,26 & \multirow[t]{3}{*}{26,725} \\
\hline & & II & 27,69 & \\
\hline & & III & 24,23 & \\
\hline & \multirow[t]{3}{*}{0,5} & $\mathrm{I}$ & 27,69 & \multirow[t]{3}{*}{26,052} \\
\hline & & II & 25,09 & \\
\hline & & III & 25,38 & \\
\hline & \multirow[t]{3}{*}{0,8} & $\mathrm{I}$ & 21,63 & \multirow[t]{3}{*}{22,784} \\
\hline & & II & 25,96 & \\
\hline & & III & 20,76 & \\
\hline & \multirow[t]{3}{*}{1,0} & $\mathrm{I}$ & 18,46 & \multirow[t]{3}{*}{19,803} \\
\hline & & II & 19,90 & \\
\hline & & III & 21,05 & \\
\hline & \multirow[t]{3}{*}{1,2} & $\mathrm{I}$ & 15,00 & \multirow[t]{3}{*}{15,381} \\
\hline & & II & 15,29 & \\
\hline & & III & 15,86 & \\
\hline \multirow[t]{21}{*}{ Consol SG } & \multirow[t]{3}{*}{0,0} & $\mathrm{I}$ & 23,65 & \multirow[t]{3}{*}{22,591} \\
\hline & & II & 22,21 & \\
\hline & & III & 21,92 & \\
\hline & \multirow[t]{3}{*}{0,1} & $\mathrm{I}$ & 30,17 & \multirow[t]{3}{*}{32,833} \\
\hline & & II & 31,95 & \\
\hline & & III & 36,38 & \\
\hline & \multirow[t]{3}{*}{0,3} & $\mathrm{I}$ & 31,95 & \multirow[t]{3}{*}{36,679} \\
\hline & & II & 36,38 & \\
\hline & & III & 41,71 & \\
\hline & \multirow[t]{3}{*}{0,5} & $\mathrm{I}$ & 41,71 & \multirow[t]{3}{*}{41,115} \\
\hline & & II & 42,59 & \\
\hline & & III & 39,04 & \\
\hline & \multirow[t]{3}{*}{0,8} & $\mathrm{I}$ & 47,03 & 44,665 \\
\hline & & II & 39,93 & \\
\hline & & III & 47,03 & \\
\hline & 1,0 & $\mathrm{I}$ & 48,81 & 46,144 \\
\hline & & II & 42,59 & \\
\hline & & III & 47,03 & \\
\hline & 1,2 & I & 43,48 & 37,270 \\
\hline & & II & 40,82 & \\
\hline & & III & 27,51 & \\
\hline
\end{tabular}




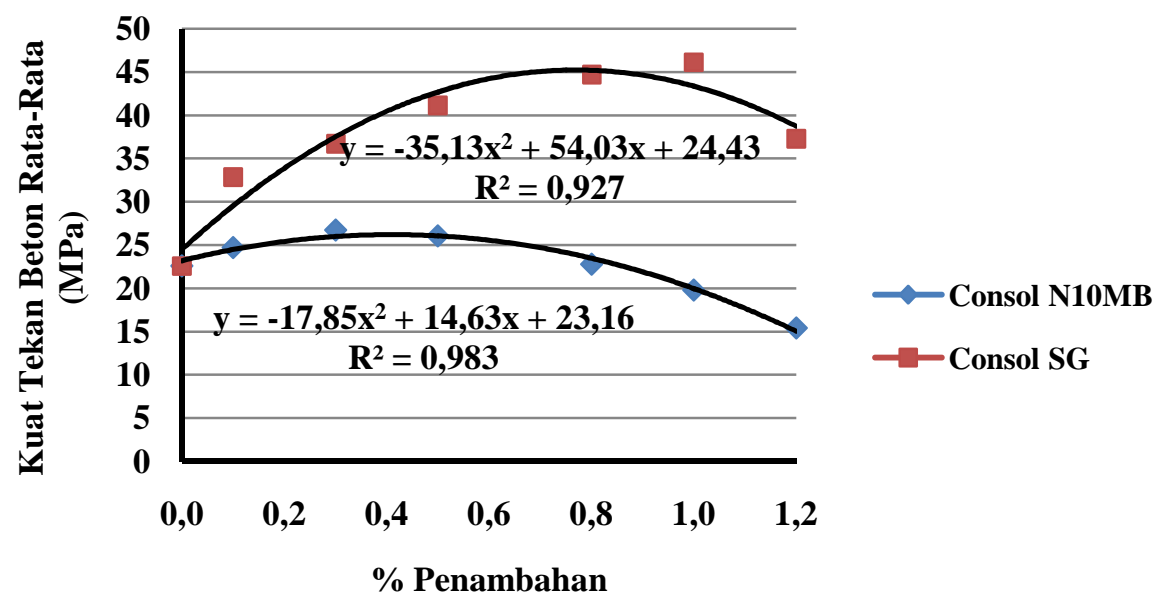

Gambar 1. Hubungan Persentase Penambahan Consol N10MB dan Consol SG terhadap Kuat Tekan Beton

Pada benda uji dengan penambahan Consol SG diperoleh peningkatan kuat tekan beton rata-rata seiring dengan penambahan \% Consol SG hingga penambahan $1,0 \%$, dengan nilai kuat tekan beton rata-rata tertinggi sebesar 46,144 MPa. Namun kemudian mengalami penurunan kekuatan tekan beton pada penambahan $1,2 \%$ Consol $\mathrm{SG}$, dengan persamaan yang diperoleh yaitu $\mathrm{y}=-35,13 \mathrm{x}^{2}+54,03 \mathrm{x}+24,43$ dengan nilai $\mathrm{R}^{2}=0,927$.

\section{E. KESIMPULAN}

Kesimpulan yang diperoleh adalah :

1. Nilai kuat tekan tertinggi pada penambahan $0,3 \%$ Consol N10MB yaitu sebesar 26,725 $\mathrm{MPa}$

2. Nilai kuat tekan tertinggi diperoleh pada penambahan $1,0 \%$, Consol SG yaitu sebesar 46,144 MPa.

\section{DAFTAR PUSTAKA}

Aprilianti,S., Nadia, 2012, Analisis Pengaruh Beton dengan Bahan Admixture Naphtalene dan Polycarboxilate Terhadap Kuat Tekan Beton Normal, Jurnal Konstruksia, Volume 3 Nomor 2 : $33-40$
Balai Jembatan dan Bangunan Pelengkap Jalan, 2011, Pedoman Pengendalian Mutu Pekerjaan Beton, Kementerian Pekerjaan Umum, Bandung.

Departemen Pekerjaan Umum, 2002, Tata Cara Perhitungan Struktur Beton Untuk Bangunan Gedung SK SNI 03-2847-2002, Departemen Pekerjaan Umum, Jakarta.

Megasari, S.W. \& Winayati, 2017. Analisis Pengaruh Penambahan Sikament-Nn Terhadap Karakteristik Beton. SIKLUS: Jurnal Teknik Sipil, 3(2), hal.117128.

Muliadi, Yanti G., Megasari SW., 2015, Analisa Perbandingan Variasi Waktu Pengadukan Terhadap Kuat Tekan Beton dengan Bahan Tambah Sika Viscocrete-3115 D, Program Studi S1 Teknik Sipil Universitas Lancang Kuning, Pekanbaru.

Mulyono T., 2005, Teknologi Beton, Ed. II, Andi, Yogyakarta.

Nugraha P., Antoni, 2007, Teknologi Beton, Andi Offset, Yogyakarta 